\title{
DE COMO ESCREVEMOS A VIDA E A VIDA SE INSCREVE EM NÓS: UM ESTUDO DA SOCIALIZAÇÃO ATRAVÉS DA ANÁLISE DE AUTOBIOGRAFIAS
}

\author{
Pedro Abrantes*
}

RESUMO: O artigo desenvolve uma abordagem biográfica dos processos de socialização, equacionando teorias clássicas e recentes das ciências sociais, à luz da análise de 53 autobiografias de trabalhadores portugueses, produzidas no quadro de um programa inovador de educação de adultos. Depois da discussão teórica e metodológica, em diálogo com avanços recentes no campo das neurociências, defende-se uma noção de socialização em três níveis distintos, ainda que articulados: emocional, prático e reflexivo.

Palavras-chave: Socialização. Método biográfico. Emoções. Práticas. Reflexividade.

\section{ON HOW WE WRITE LIFE AND LIFE IS INSCRIBED IN US: A STUDY OF SOCIALIZATION THROUGH THE ANALYSIS OF AUTOBIOGRAPHIES}

ABSTRACT: A biographical perspective on socialization processes is developed in this paper, discussing classic and recent theories in the Social Sciences, in the light of an analysis of 53 Portuguese workers' autobiographies, carried out under an innovative adult education program. After a theoretical and methodological discussion, in dialogue with recent advances in neuroscience, a concept of socialization is sketched, which is organized in three distinct - although articulated - levels: emotional, practical and reflective.

Key words: Socialization. Biographical method. Emotions. Practices. Reflectivity.

Universidade Aberta e Centro de Investigação e Estudos de Sociologia do Instituto Universitário de Lisboa. Lisboa - Portugal.

Contato com o autor: <pedro.abrantes@uab.pt> 
De como escrevemos a vida e a vida se inscreve em nós...

\title{
De COMME NOUS ECRIVONS LA VIE ET LA VIE S'INSCRIT \\ DANS NOUS: UNE ETUDE DE LA SOCIALISATION A TRAVERS \\ L'ANALYSE D'AUTOBIOGRAPHIES
}

\begin{abstract}
RÉSUMÉ: L'article développe un abordage biographique des procédures de socialisation, en égalant théories classiques et récentes des sciences sociales, à l'égard de l'analyse de 53 autobiographies de travailleurs portugais, produites dans le cadre d'un programme innovateur d'éducation d'adultes. Après la discussion théorique et méthodologique, en dialoguant avec les progrès récents dans le champ des neurosciences, on défend une notion de socialisation à trois niveaux distincts, bien qu'articulés : émotionnel, pratique et réfléchi.
\end{abstract}

Mots-clés: Socialisation. Méthode biographique. Émotions. Pratiques. Réflexivité.

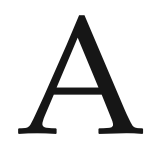

socialização é o processo através do qual participamos no mundo social e, em simultâneo, incorporamos linguagens, disposições e valores que favorecem essa participação. Mas como interpretamos, organizamos e ativamos as sucessivas experiências? Todas elas têm o mesmo valor? Que fatores pesam na estruturação do eu socializado? E de que forma as autobiografias nos podem revelar aspetos da socialização dos indivíduos? Será a consciência autobiográfica um mero subproduto da socialização ou é também orientador deste processo?

Sendo o conceito de socialização central no projeto das ciências sociais, o conhecimento de que dispomos para responder às questões anteriores é ainda escasso, o que, aliás, tem dado azo a explicações do comportamento social dos indivíduos pelo genético ou pelo económico que continuam a influenciar o senso comum, dispondo de ampla visibilidade no espaço editorial e nos mídia (LAHIRE, 2005).

Este problema orientou o projeto de investigação que desenvolvi, entre 2010 e 2012, inspirado em obras clássicas da Sociologia, como Elias (1994), Berger e Luckmann (1998) ou Bourdieu (1979), assim como em um conjunto de pesquisas recentes que se têm igualmente centrado nos processos de socialização (DUBAR, 2005), na formação de disposições (LAHIRE, 2002 e 2005), na "aprendizagem situada" (LAVE; WENGER, 1995) ou na educação informal (ECCLESTONE; BIESTA; HUGHES, 2010). Se a terminologia varia, consoante as escolas de pensamento, não há dúvida que o objeto de fundo que procuram analisar é o mesmo. De notar que a revista $E d u-$ cação $\mathcal{E}$ Sociedade tem constituído um espaço fundamental na revitalização das discussões sobre este tema (MOLLO-BOUVIER, 2005; BARBOSA, 2007; GHEORGHIU; GRUSON; VARI, 2008; PRESTO; ALMEIDA, 2008).

A revisão teórica permitiu-me constatar que, se a visão clássica da socialização como incorporação mecânica "do social", em resultado de práticas e relações inexoráveis, tem suscitado inúmeras críticas, algumas perspectivas recentes 
atribuem um papel central à reflexividade e à identidade, nem sempre reconhecendo que estas se vão construindo ao longo da vida, a partir das condições e contextos em que os sujeitos se integram. Por seu lado, procurando equilibrar estes dois polos, a conhecida distinção entre a socialização "primária" e "secundária" (BERGER; LUCKMANN, 1998) não revela um suporte empírico muito forte: não apenas a infância se tende hoje a caracterizar por um contato com diversos atores, instituições e "mundos especializados" (BARBOSA, 2007), mas também a idade adulta é atravessada por mudanças tão drásticas que produz uma socialização que não se pode reduzir à adaptação, racional e voluntária, a certas "regiões de significado" (ECCLESTONE; BIESTA; HUGHES, 2010; ABRANTES, 2013).

Nesta busca por aprofundar o conhecimento sobre o processo de socialização foi também importante o contato com avanços recentes no campo das neurociências, que nos convidam a um diálogo interdisciplinar, ao explorar o papel central das emoções e a existência, no cérebro humano, de uma memória (e uma consciência) autobiográfica, responsáveis por uma regulação vital mais sofisticada e eficaz (DAMÁSIO, 2010; CASTAINGTS, 2011).

O atual projeto baseou-se nas três seguintes premissas: (1) as experiências em que o indivíduo se envolve são apenas uma fração (parcial, mas não aleatória) do social; (2) o impacto dessas experiências na formação do indivíduo depende da sua capacidade e disposição (variáveis) de interpretar e interpelar o social; (3) estas experiências são sempre únicas e geram uma quantidade tão grande de informação que supõem processos (internos e intersubjetivos) de seleção (memória/esquecimento), generalização e analogia.

\section{O estudo}

A observação sistemática dos processos de socialização é uma empresa extremamente complexa, pelo que cada projeto apenas pode almejar a uma abordagem parcelar que, em diálogo com a restante pesquisa, contribua para o avanço paulatino e coletivo do conhecimento. No caso do presente projeto, tanto por razões teóricas como empíricas, a abordagem privilegiada foi a análise das narrativas autobiográficas de um conjunto de indivíduos da classe trabalhadora portuguesa.

Em termos teóricos, interessava-me aprofundar o modo como os indivíduos, na definição do eu, vão inscrevendo e organizando as experiências em que participam ao longo da vida e, a partir delas, constroem as competências, as disposições e os valores que marcam a sua trajetória e identidade no espaço social. Esta perspectiva permite colocar em diálogo teorias das ciências sociais e das neurociências (como já dito) sobre o processo de socialização com os avanços recentes no 
campo interdisciplinar dos estudos biográficos (BERTAUX, 1981; PUJADAS, 1992; ARFUCH, 2002; ECCLESTONE; BIESTA; HUGHES, 2010).

É verdade que uma parte importante das experiências é armazenada em disposições inconscientes e que as narrativas autobiográficas que podem ser recolhidas por um investigador são sempre uma forma de "apresentação de eu" ante o(s) outro(s) (GOFFMAN, 1993), também ela socializada pelas narrativas autobiográficas com que o indivíduo contata, através de conversas informais, da mídia e da arte. No entanto, defendemos que o modo como o indivíduo define a sua história contém elementos fundamentais da sua experiência e, sobretudo, de como ele a interpreta, a organiza e a mobiliza, na sua formação como ator social. Além disso, como a linguística ou a psicanálise têm aprofundado, uma análise de conteúdo destas narrativas permite explorar os registos discursivos, as omissões, as sublimações, os encadeamentos não intencionais, o que nos aponta pistas fundamentais sobre processos de formação do inconsciente (ARFUCH, 2002).

Em termos empíricos, cerca de meio milhão de portugueses com baixa escolaridade produziram a sua autobiografia, ao longo da última década, no âmbito de um processo inovador de educação de adultos, de forma a completar o ensino básico ou secundário (Processo RVCC, Iniciativa Novas Oportunidades). Em geral, são trabalhos longos e detalhados (entre 50 e 200 páginas), resultantes de reflexões realizadas ao longo de vários meses, apoiadas por técnicos especializados (educadores, psicólogos, sociólogos, entre outros) e que procuram relacionar as histórias de vida com o desenvolvimento de competências, disposições e valores, pelo que casam bem com os objetivos da pesquisa (ABRANTES; ANÍBAL; PALIOTES, 2010). Além disso, se raramente os estudos clássicos sobre a socialização utilizaram dispositivos sistemáticos de observação empírica, os estudos mais recentes privilegiam as entrevistas em profundidade, o que, sendo um instrumento virtuoso, está longe de esgotar os registos úteis para analisar os processos de socialização.

Comecei por identificar e contatar quatro Centros Novas Oportunidades (organizações locais responsáveis pela implementação deste sistema de educação de adultos), com enquadramentos institucionais e territoriais muito distintos:

- Associação empresarial em Lisboa, servindo uma população urbana e empregada nos serviços;

- Centro de formação no Barreiro, um subúrbio operário, com um forte crescimento entre os anos de 1940 e 1970, sobretudo, pelo estabelecimento de indústrias pesadas;

- Escola secundária em Torres Vedras, região agrícola e à qual acorrem muitas pessoas ocupadas no setor primário e comerciantes; 
- Associação de desenvolvimento local, no Entroncamento, pequena cidade na qual convergem os três setores de atividade.

Em cada organização, solicitei os contatos telefónicos de uma amostra de 15 formandos, diversificada, em termos de idade, sexo, categoria socioprofissional e grau de escolaridade a obter (básico ou secundário). Contatámos estes adultos, no sentido de nos disponibilizarem todo o material produzido no âmbito do reconhecimento de competências, sendo que acabámos por trabalhar com um "corpus" de 53 histórias de vida, de perfis sociais diversificados (todos com baixos níveis de escolaridade), perfazendo 3.930 páginas. Cada autobiografia foi objeto de uma análise de conteúdo, em cinco passos:

(1) Listagem da sequência de capítulos, secções e tema principal em cada parágrafo/imagem, detalhando a dimensão e o tipo de registo privilegiado (factual, opinativo, reflexivo, emocional);

(2) Agregação destes parágrafos e imagens em temáticas específicas;

(3) Gráfico, localizando os temas agregadores identificados segundo a sua dimensão, posição na autobiografia (eixo vertical) e arco cronológico a que se reportam (eixo horizontal);

(4) Quadro-síntese com os principais temas narrados, colocando em linha a dimensão da vida (família, educação, trabalho, lazer e comunidade/sociedade) e em coluna a faixa etária $(0-10,11-15,16-20,21-40,>40)$ a que se refere.

(5) Análise específica das principais dimensões identificadas, consoante a informação sobre cada uma delas (por exemplo, na área do trabalho foi possível fazer um gráfico que representa o percurso profissional de cada indivíduo).

O fato de a produção destes trabalhos não ser orientada pelos investigadores, mas por referenciais e profissionais de educação de adultos, constitui uma limitação que procurámos dirimir por uma análise complementar dos documentos orientadores e entrevistas a alguns dos técnicos. Porém, as entrevistas biográficas realizadas por investigadores não deixam de condicionar as narrativas dos sujeitos. A circunstância dos indivíduos construírem um documento volumoso para dar conta da sua vida e aprendizagens constitui um material precioso para a análise sociológica, até pelo tempo que investiram na identificação, hierarquização e articulação das experiências que consideram mais marcantes para a sua formação como profissionais e cidadãos.

Como se aprofunda num livro publicado recentemente (ABRANTES, 2013), esta análise centrou-se então na relação das histórias de vida com a formação de 
competências, disposições e valores, em determinadas instituições, algumas já expectáveis, como é o caso da família, do ensino ou do trabalho, e outras talvez mais surpreendentes, como os rituais de transição, o serviço militar, o desporto ou os grupos de amizade. Além disso, permitiu-nos explorar como certas categorias analíticas, como a transformação social, o território, o género, a geração e a estrutura de classes, condicionam não apenas as experiências e trajetos vitais, mas, sobretudo, o modo como estes são interpretados, narrados e relacionados, ainda que os sujeitos tenham uma consciência apenas parcial e variável sobre essa influência.

Não sendo possível num artigo detalhar os resultados em cada dimensão, iremos dedicar as restantes páginas a uma teorização geral do processo de socialização, a partir da análise teórico-empírica realizada. Esta teorização baseia-se na ideia de que a socialização é regulada em três níveis centrais: o emocional, o prático e o reflexivo.

\section{Emoções}

Afirma Damásio (2010) que, desde que exista suficiente emoção numa determinada experiência, somos capazes de a registar na memória e de ativá-la, posteriormente. Uma teoria da socialização que dialogue com as neurociências deve então considerar que os mecanismos emocionais são centrais no processo de inscrição, seleção e mobilização de experiências. Uma parte importante deste processo ocorre num nível inconsciente, mas é interessante como influem, de diversas formas, nas autobiografias. Aliás, é significativo que, na introdução ou na conclusão, muitos dos seus autores afirmam ter sentido emoções intensas (frequentemente, assinaladas pelo choro), durante a produção das suas histórias de vida, ao recordar e escrever certas passagens da sua vida.

O caso mais evidente desta relação entre emoções e socialização é o registo minucioso de situações de risco de morte, das aprendizagens e dos traumas que delas decorrem, como as investidas na guerra colonial (vivida pelo segmento masculino mais velho), as doenças e acidentes graves, do próprio ou de familiares próximos.

Não irei falar dos fatos mais agressivos daquela guerra para com a minha pessoa, pois são casos para nos tentarmos esquecer, só que não conseguimos [...] ficaram sempre gravadas, memorizadas, no nosso subconsciente e como me é habitual dizer: estão gravadas no disco rígido e nem mesmo com uma formatação profunda, se conseguem apagar, é como se tivessem ocorrido ontem, precisamente, isto é, todos os dias após o deitar, cá estão elas, a vir à memória. (Maquinista/chefe de depósito - homem, 61 anos)

Nesse tempo, não havia brinquedos nem alimentos como existem agora, mas mesmo que os houvesse o dinheiro não chegava para adquiri-los. A pobreza em que as crianças e os pais viviam era enorme, morriam muitas crianças porque os pais não tinham dinheiro 
para levá-las ao médico. Fui a muitos funerais quando era pequena e isso foi das coisas que mais me marcou. (Comerciante - mulher, 63 anos)

Outro caso é aquele em que o confronto com uma mudança brusca no contexto de vida suscitou um aumento da excitação e/ou da ansiedade, redobrando assim a capacidade de inscrição das experiências, de forma a adaptar rapidamente as disposições a um novo contexto. Esse fenómeno é evidente nas referências à primeira experiência laboral, à mudança do campo para a cidade ou à primeira viagem ao estrangeiro.

O vínculo entre emoções e socialização confere também a certos eventos uma importância capital na formação das identidades e autobiografias. Não será surpreendente que, nas histórias de vida, eventos como o exame da quarta classe, a primeira comunhão, o juramento da bandeira, o casamento ou o funeral de um dos pais constituam elementos centrais, com direito a várias páginas, geralmente povoadas de fotografias. Alguns destes eventos ganham um simbolismo particular, pois representam, para os indivíduos, o processo de transição para a vida adulta (GUERREIRO; ABRANTES, 2005) e/ou alterações significativas nas suas "fronteiras imaginadas" (PRESTO; ALMEIDA, 2008). Como haviam estudado Durkheim (1965) ou Connerton (1989), trata-se de rituais programados com minúcia e recordados com frequência para testar e sublimar a integração dos indivíduos na sociedade e (re)definir a sua identidade, em que a "efervescência coletiva" garante níveis emocionais que ampliam o potencial socializador. Além disso, há efetivamente um conjunto de competências, disposições e valores, cuja adesão e incorporação são colocadas à prova e celebradas nestas circunstâncias, tornando-se estruturantes na formação do $e$.

A festa [casamento] foi muito agradável, com os amigos e a família à nossa volta, a felicidade sentia-se no ar e a expectativa de uma vida perfeita era o sentimento do momento. (Pedreiro, 40 anos)

A vertente emocional da socialização é ainda visível na importância de certas relações na (re)definição do eu e do "seu" mundo. As memórias da infância estão fortemente ancoradas a figuras de referência, como pais, avós, irmãos, entre outros. Mas também as experiências escolares, desportivas, militares ou laborais se encontram marcadas por laços sentimentais, apresentados como decisivos para as competências, identidades e valores desenvolvidos. Estes elos podem ser positivos, inspirando uma aprendizagem por identificação e compromisso, ou negativos, alimentando uma socialização por subordinação, distinção e/ou competição (ver tópicos seguintes).

Outro tipo importante de emoções tem a ver com aquelas que são associadas a ações educativas. Vários trabalhadores mais velhos notam que as aprendizagens 
escolares, nos anos de 1950 e 1960, estavam ancoradas a fortes sentimentos de medo e vergonha. Os castigos físicos e simbólicos às crianças que não aprendessem a lição eram tremendos. Este, aliás, é um princípio fundamental, por exemplo, no adestramento de animais. Trata-se de uma manipulação, por parte do educador, do tal instinto de aprendizagem pela indução de um risco físico e/ou psicológico.

Será útil ponderar, como Ferrés i Prats (2008), se a remoção dos instrumentos mais cruéis que impunham esse medo, sem o desenvolvimento paralelo de técnicas que suscitem o desejo, pelo menos no mesmo grau de intensidade, não será responsável pela sensação que temos hoje de que os jovens aprendem menos nas escolas, sobretudo numa era em que a mídia tem aparelhos cada vez mais sofisticados de socialização, precisamente, pela via do desejo. Muitos dos trabalhadores que cresceram já nos anos de 1980 e 1990 documentam o aborrecimento da escola como um fator importante do seu insucesso, em contraste com os estímulos intensos, noutras esferas da vida. Daí vai um passo ao envolvimento em modos juvenis de socialização paralela, geradores de sentimentos fortes de medo e desejo, logo de aprendizagem e integração (WILLIS, 1977; ABRANTES, 2003). Todavia, muitos jovens destacam também agentes e atividades escolares que lhes suscitaram emoções positivas e aprendizagens duradouras, enquanto conflitos com certos agentes e disciplinas produziram emoções negativas que, em muitos casos, inibiram aprendizagens e alimentaram a convicção da sua incapacidade para a escola que induziu o seu abandono. Mesmo quando desprovidas do seu carácter brutal, as sanções escolares levam frequentemente a uma inibição das aprendizagens escolares por fraca autoestima ou a uma resistência à sua importância, precisamente, como estratégia de preservação do que resta da "segurança ontológica" (GIDDENS, 1994).

Por fim, a análise confirmou estudos recentes sobre as relações entre emoções e estrutura social, segundo os quais a mobilidade ascendente se associa a sentimentos de segurança e satisfação, ao passo que a mobilidade descendente gera sentimentos de cólera e embaraço (TURNER; STETS, 2006). É relevante como as narrativas autobiográficas de jornaleiros agrícolas que se tornaram técnicos e empregados dos serviços são impregnadas de otimismo, enfatizando os elementos mais positivos de cada experiência, enquanto as histórias de vida escritas por desempregados ou trabalhadores subalternos que cresceram em famílias da classe média estão dominadas por críticas e ressentimentos, ora a si mesmos, ora a outras pessoas, instituições ou transformações.

\section{Práticas}

Embora a socialização inclua todas as experiências no mundo social, a participação regular em práticas constitui um espaço privilegiado para os indivíduos desenvolverem disposições e representações do mundo e de si mesmos (BOURDIEU, 
1980, 1987; GIDDENS, 1990). Por um lado, com os seus materiais, símbolos e protocolos próprios, as práticas possuem uma "lógica interna", cimentada ao longo do tempo e que vincula as ações dos sujeitos às estruturas sociais (e às condições de existência). Por outro, a participação regular implica aceitar e interiorizar essa lógica, impulsionando o desenvolvimento de disposições corporais, mentais e emocionais afins, em grande medida inconscientes e performativas, assim como o sentimento de pertença a uma comunidade e o reconhecimento de uma posição e papel específicos no seu interior.

Inicialmente, os indivíduos incorporam-se em práticas simples, sendo a sua participação periférica e mimética. Progressivamente, através do envolvimento repetido, se vão criando disposições que permitem um maior protagonismo, assim como uma integração em práticas mais complexas, o que torna o indivíduo um exemplo para os recém-ingressados (LAVE; WENGER, 1995).

É verdade que, ao contrário das emoções, estas práticas ficam muitas vezes negligenciadas nas narrativas autobiográficas. No entanto, em parte pelo trabalho de orientação dos profissionais, os trabalhos analisados enfatizam a importância de certas práticas para o desenvolvimento de disposições, competências e valores. Isto é observável no modo como os trabalhadores portugueses descrevem a sua integração gradual nas atividades familiares e que incluiu, em muitos casos, a participação em atividades produtivas, quando os pais eram agricultores ou comerciantes. Mesmo quando a transformação social, a migração e a mobilidade profissional fizeram com que as competências laborais aprendidas não tivessem tanta utilidade direta como o esperado, os valores transmitidos pelos pais e por outros adultos, no decurso dessas práticas, são considerados fundamentais na construção biográfica do eu. De notar que este carácter "totalitário" de certas experiências de socialização primária não rompe as possibilidades de os agentes a reinterpretarem ao longo do curso de vida e parece desvanecer entre as gerações mais jovens, em que a infância decorreu já num contexto pluri-institucional.

Também algumas práticas em contexto desportivo e militar, sobretudo no caso dos homens, são descritas com minúcia e orgulho, enquanto génese (mitificada?) de disposições, identidades e valores adultos, sublimados na expressão recorrente: "foi na tropa que me tornei homem". No caso das mulheres, existe um retraimento maior, por exemplo, em narrar e refletir sobre as aprendizagens precoces decorrentes da vida doméstica, talvez pelo reduzido valor social que é atribuído a estas esferas como geradoras de competências e valores ou, inclusive, por uma estratégia de demarcação relativamente a mães e avós, num esforço de apresentação pública como "mulheres modernas", refletindo as profundas transformações nas relações de género ocorridas nas últimas décadas. 
Considero esta passagem pela minha vida militar e pela grande escola que é a Força Aérea, pois, com muita sinceridade, deram-me um grande suporte para a minha vida, quer a nível profissional, quer a nível de camaradagem, quer a nível do homem que consegui ser, aliás reconhecido pelos meus comandantes, através dos louvores que se seguem e me enchem de muito orgulho. (Maquinista ferroviário, 62 anos)

Também joguei futebol nas camadas jovens do Casalinhense. Com isso aprendi a ouvir, a definir prioridades, a ser optimista, a ter confiança em mim e nos meus companheiros de equipa. $\mathrm{O}$ trabalho em equipa valoriza cada indivíduo e permite que todos façam parte de uma mesma ação. Por último, possibilita a troca de conhecimento e experiência. (Vendedor de betão, 39 anos)

É um trabalho que não dá descanso e embora haja rotinas a cumprir, os turnos nunca são iguais. Há uma entrega muito grande ao trabalho e aos utentes. Está-se sempre a aprender, até porque a ciência está sempre em evolução e obriga-nos a uma atualização constante. A mente humana está sempre em funcionamento, e surgem com muito mais frequência novas técnicas terapêuticas. (Auxiliar hospitalar - mulher, 61 anos)

Já as práticas escolares surgem, sobretudo, associadas à produção de bloqueios e desconfianças face ao saber formal (ou à capacidade pessoal e utilidade social da sua aquisição, não isenta de ressentimentos). Lembramos que o trabalho foi realizado com trabalhadores com baixo nível de escolaridade; é possível que os resultados fossem diferentes junto de outras classes sociais. Em todo caso, as práticas de escrita/ leitura e da aritmética, desenvolvidas na escolaridade primária e ativadas depois ao longo da vida, constituem uma experiência socializadora fundamental na forma de interpretar (e agir sobre) o mundo (LAHIRE, 2002) que, na classe trabalhadora portuguesa, contrasta muitas vezes com a socialização dos familiares mais velhos. Assim, facilitou movimentos migratórios e a integração numa vida urbana, letrada e moderna, ainda que num estatuto subalterno. Além disso, algumas disciplinas e professores singulares conseguem gerar práticas que perduram nas disposições dos indivíduos, sobretudo quando estabelecem um vínculo entre saberes formais e competências úteis na vida quotidiana.

\footnotetext{
Nesta nova disciplina (educação tecnológica, $7^{\circ}$ ano) lembro-me de começar a aprender como funcionavam os circuitos elétricos de uma casa, como funcionava uma lâmpada, etc. Como era uma aula com um conteúdo mais na base da prática do que da teoria, eu gostava muito porque eu aprendia mais a mexer e a experimentar do que se estivesse ali sentado apenas a ouvir o professor. (Secretário, 32 anos)
}

As práticas relacionam-se com as emoções de várias formas. A interiorização de certos procedimentos pela rotina inibe emoções negativas, contribuindo para a segurança e bem-estar do indivíduo. Além disso, tal economia emocional e cognitiva permite ao indivíduo aperfeiçoar continuamente a prática (e os sistemas cognitivos e corporais associados), tecendo elementos que haviam ficado fragmentados nas primeiras experiências, ensaiando variações originais e resolvendo problemas. Dessa forma, desenvolve-se uma identidade, associada muitas vezes a benefícios simbólicos e/ou 
materiais. Ao gerar espaços de ação criativa e de reconhecimento social, a participação em práticas diferencia-se da mera repetição rotineira de atividades, constituindo uma fonte de emoções positivas. Em simultâneo, o fracasso na integração em certas práticas é também gerador de frustrações, ressentimentos e traumas.

Importa notar que a socialização pela prática constitui um processo lento e que, no contexto laboral, entra hoje em tensão com a enorme rotatividade dos postos de trabalho desqualificados, numa economia em ebulição. Alguns dos trabalhadores mais jovens da amostra demonstram trajetórias de circulação entre distintos trabalhos e períodos de desemprego, com pouco acesso a práticas profissionais estáveis que favoreçam essa formação de competências, identidades e valores, o que não deixa de afetar a sua capacidade produtiva, num círculo vicioso de desqualificação e desfiliação.

\section{Reflexividade e identidade}

A reflexividade, como capacidade dos indivíduos se pensarem a si mesmos e ao mundo através de um "diálogo interior", tem sido enfatizada pela sociologia contemporânea, por vezes até em oposição a uma noção demasiado mecânica e estruturalista da socialização (GIDDENS, 1994; PINTO, 2008; CAETANO, 2011). Porém, não há qualquer incompatibilidade entre ambos os processos. Ao invés, a reflexividade e a construção de uma identidade dependem de experiências prévias de socialização e têm um papel regulador sobre o processo socializador.

Isso implica aceitar que a reflexividade não é um domínio individual, mas um espaço socialmente construído, de representações, ideologias, racionalidades... E se é verdade que a escrita e a leitura foram uma importante alavanca dos processos reflexivos, promovendo níveis de abstração que associamos à razão moderna, não devemos menosprezar a existência anterior de reflexão e intersubjetividade, nem o peso que as crenças, os estereótipos e os preconceitos continuam a jogar nos circuitos de reflexividade, hoje altamente midiatizados. Do mesmo modo, reconhecer que as identidades se tornaram centrais na vida moderna e que a liberdade dos atores para as forjarem se alargou, não significa pensar que as identidades constituem uma construção livre e instantânea, desenraizada da trajetória dos indivíduos no espaço social e pelos diferentes contextos em que ocorre a sua socialização (BOURDIEU, 1979; LAHIRE, 2002).

Nas autobiografias analisadas, esta reflexão e subjetividade coletivas são, desde logo, observáveis no modo como a narrativa é construída, iniciando quase sempre a história de vida com o nascimento, seguido de uma série de acontecimentos com uma forte carga dramática e emotiva (ver o tópico "Emoções"), organizados em geral por capítulos que dizem respeito ora a etapas vitais (infância, adolescência, idade 
adulta...), ora a contextos institucionais (familiar, profissional, religioso, desportivo, militar, entre outros). Se esta organização nos parece natural é, apenas, porque a temos incorporado, no quadro da cultura em que vivemos: veja-se como, noutros tempos e noutras sociedades, a infância e adolescência não se afirmavam como etapas autónomas (MEAD, 1927; CORSARO, 2005), assim como não eram nítidas as divisões entre identidades e contextos de vida que dão hoje origem a "atores plurais" (LAHIRE, 2002).

Mesmo nas narrativas recolhidas é possível observar diferenças geracionais importantes, sendo a transformação social profunda das últimas décadas um forte gerador de reflexividade e de produção de identidades distintivas. Muitos dos trabalhadores mais velhos, por exemplo, discorrem longamente sobre a violência de que eram vítimas na escola e na família, lamentando o facto de não terem as mesmas oportunidades que os jovens de hoje. A sua condição desfavorecida é, assim, vivida como um desígnio coletivo, ditado pelos poderosos e atenuada por uma longa luta de afirmação pessoal. Não raramente, estas narrativas assumem um tom épico e heroico, fruto de uma estratégia de resistência face à descriminação e desvalorização de que são alvo. Mas observa-se também que muitos deles, sobretudo durante a juventude (na tropa, nos primeiros empregos e na mídia), experimentaram processos profundos de ressocialização "entre pares" ou "antecipatória", num trabalho sistemático "sobre si", alimentado por expectativas de mobilidade social ascendente pela aquisição de valores modernos e urbanos, não isentos de tensões e distanciamentos em relação a pais e avós, representantes da classe camponesa e comerciante de uma sociedade tradicional em acelerada erosão. Mais do que uma mudança abrupta das condições objetivas, a Revolução Democrática de 1974 constituiu um "marco simbólico" desta transição entre o velho (estigmatizado) e o novo mundo (fonte de esperanças), nas classes desfavorecidas.

Já os trabalhadores mais jovens tendem a explicar o seu abandono escolar por rasgos psicológicos próprios ou pelo papel nocivo de pessoas concretas (o pai, o professor, o patrão, os amigos, entre outros), no quadro do "individualismo institucionalizado" (BECK; BECK-GERNSHEIM, 2003). Não significa que as forças sociais deixem de atuar sobre eles, nem que se tornem seres egoístas e egocêntricos, mas a sua socialização, em instituições modernas, alimenta uma reflexividade centrada nas escolhas e responsabilidades individuais, na construção do eu. Mais dóceis e difusos, os processos coletivos de exploração e dominação surgem frequentemente ofuscados, ante uma ideia ampliada do poder de agência dos sujeitos, muito difundida hoje pela mídia.

Porém, esta nova racionalidade favorece também o sentido crítico face às formas mais violentas de opressão, sejam as perpetradas na família, na empresa ou no Estado, na linha da tese de Elias (1989) sobre a relação entre a individualização e o processo civilizacional. 
Também as diferenças de género moldam a reflexividade e a construção identitária. Enquanto os homens valorizam a importância da participação comunitária e das práticas de lazer, para o seu bem-estar pessoal e para a definição de um eu distintivo, as mulheres tendem a minorar as suas possibilidades nestes contextos, face às responsabilidades que assumem, na casa, na família e no trabalho. Aliás, um aspecto que parece distintivo na construção das identidades femininas em Portugal, mesmo nas classes mais desfavorecidas, em contraste com outros países da Europa do sul, é a centralidade do trabalho (pago) na afirmação do "eu-mulher" (TORRES, 2009), o que de igual forma acrescenta dramatismo ao aumento recente do desemprego, decorrente da atual crise financeira (SOUSA SANTOS, 2011).

\footnotetext{
Neste balanço, concluo que não tenho a vida que imaginei, não sou quem queria ser e tenho tido mais fracassos do que sucessos. Estou a tentar inverter este processo e espero conseguir: o processo de reconhecimento, validação e certificação de competências faz parte dessa tentativa de inverter o sentido da minha vida. (Pedreiro, 40 anos)

Com a atual crise económica que o país atravessa, diariamente somos confrontados com notícias de despedimentos, de fábricas a fechar, de famílias inteiras no desemprego. Muitos deles, sem meios de subsistência, sem valorização profissional e pessoal, não têm meios para colocar de novo a máquina em andamento, nos carris da vida. Para esses, a vida pára. Que faríamos nós, sem trabalho? É impensável sobreviver assim. (Assistente administrativa, 50 anos)
}

Em suma, entrelaçadas com as emoções e as práticas, a reflexividade e a construção da identidade constituem um elemento orientador dos processos de socialização, assente em crenças, valores, ideologias e conhecimentos, simultaneamente pessoais e coletivos. Por um lado, a experiência social fomenta (e condiciona) o modo como o indivíduo se pensa a si mesmo e ao mundo que o rodeia. Por outro, essa intersubjetividade permite ao indivíduo interpretar as experiências vividas e, em parte, escolher as experiências que pretende que o socializem. Isso é claro, por exemplo, na concepção das "boas" e "más companhias", bem como no investimento crescente em processos educativos formais (cursos, workshops, entre outros) como estratégia de restauração e transformação do eu, numa busca por "reescrever" a história pessoal (ECCLESTONE; BIESTA; HUGHES, 2010).

\section{Conclusões}

Através de um diálogo entre teoria e observação, o artigo apresentou alguns contributos para o estudo da socialização, focando a sua dimensão (auto)biográfica. Desta forma, procurámos conciliar perspectivas mais estruturalistas e "praxiológicas" da socialização com propostas que têm privilegiado a ação e a reflexividade, além de explorarmos o papel que as emoções podem jogar neste processo, em 
diálogo com avanços recentes das neurociências. Sem dúvida que a socialização dos indivíduos vai muito além daquilo que podem expressar na sua autobiografia, por mais completa que seja. Por exemplo, será fundamental aprofundarmos o estudo da socialização durante os primeiros anos de vida, dado que aí se produzem experiências fundamentais na estruturação do eu, que escapam à consciência (CICOUREL, 2007). Em todo caso, a autobiografia não deixa de constituir um dos produtos mais completos (e complexos) da socialização e coloca em evidência um trabalho contínuo dos indivíduos sobre si mesmos, no sentido de interpretarem e organizarem o seu processo de socialização, com vista à sua mobilização prática e apresentação pública.

A tipologia de três níveis de socialização que estrutura a nossa proposta tem alguns paralelismos com a teoria de Damásio (2010) sobre a organização da consciência humana em "proto-eu", "eu nuclear" e "eu autobiográfico" e, inclusive, com a tipologia freudiana: $i d$, ego e superego (FREUD, 1961). Porém, a psicanálise e as neurociências tendem a remeter a importância da sociedade apenas para o último destes níveis, fazendo-a depender da aquisição da língua e de outros códigos simbólicos sofisticados, ao passo que, como resulta claro neste artigo, pensamos que o social é um elemento constitutivo central dos três níveis, em interação contínua com o desenvolvimento biológico. Será importante aprofundarmos este diálogo interdisciplinar, assim como explorar as formas de articulação - e as possíveis disjunções - entre estes três níveis de socialização.

Também a pesquisa empírica poderá ser aprofundada, nos próximos tempos, em dois diferentes sentidos. Por um lado, será útil cruzar a presente análise com outras técnicas de pesquisa, como a realização de entrevistas em profundidade, não apenas ao próprio sujeito, mas também a indivíduos que o acompanharam, de perto, em particular, nos primeiros anos de vida. Por outro, será preciso comparar os resultados obtidos com aqueles que se podem recolher de produções similares, noutras sociedades, tempos históricos e classes sociais, de forma a identificar singularidades da classe trabalhadora portuguesa ou, pelo contrário, aspetos mais transversais na socialização dos indivíduos, entre tempos, culturas e classes. Desta forma, poder-se-á continuar a aprofundar a relação dos processos de socialização com a transformação sócio-histórica (ELIAS, 1994), a estrutura de classes (BOURDIEU, 1979) e/ou os quadros culturais mundiais (INGLEHART, 2006).

\section{Referências}

ABRANTES, P. Os sentidos da escola: identidades juvenis e dinâmicas de escolaridade. Oeiras: Celta, 2003. 
ABRANTES, P. A escola da vida: socialização e biografia(s) da classe trabalhadora. Lisboa: Mundos Sociais, 2013.

ABRANTES, P.; ANÍBAL, A.; PALIOTES, F. Do método biográfico em Sociologia da Educação. Sociologia da Educação - Revista Luso-Brasileira, Rio de Janeiro, n. 2, p. 5-31, 2011.

ARFUCH, L. El espacio biográfico: dilemas de la subjetividad contemporánea. Buenos Aires: Fondo de Cultura Económica, 2002.

BARBOSA, M.C. Culturas escolares, culturas de infância e culturas familiares: as socializações e a escolarização no entretecer destas culturas. Educação E Sociedade, Campinas, v. 28, n. 100, p. 1059-1083, 2007.

BECK, U.; BECK-GERNSHEIN, E. La individualización: el individualismo institucionalizado y sus consecuencias sociales y políticas. Barcelona: Paidós, 2003.

BERGER, P.; LUCKMANN, T. A construção social da realidade. Petrópolis: Vozes, 1998. BERTAUX, D. (Ed.). Biography and society: the life history approach in the social sciences. London: Sage, 1981.

BOURDIEU, P. La distinction: critique social du jugement. Paris: Minuit, 1979.

BOURDIEU, P. Le sens pratique. Paris: Minuit, 1980.

BOURDIEU, P. Esquisse d'une théorie de la pratique. Genève: Droz, 1987.

BOURDIEU, P. Science de la science et reflexivité. Paris : Raison d'Agir, 2001.

CAETANO, A. Para uma análise sociológica da reflexividade social. Sociologia, Problemas e Práticas, Lisboa, n. 66, p. 157-174, 2011.

CASTAINGTS, J. Antropología simbólica y neurociencia. Barcelona: Anthropos, 2011.

CICOUREL, A. As manifestações institucionais e cotidianas do habitus. Tempo Social: Revista de Sociologia da USP, São Paulo, v. 19, n. 1, p. 169-188, 2007.

CONNERTON, P. How societies remember. Cambridge: Cambridge University, 1989.

CORSARO, W. The sociology of childhood. Thousand Oaks: Pine Forge, 2005.

DAMÁSIO, A. O livro da consciência: a construção do cérebro consciente. Lisboa: Temas \& Debates, 2010.

DENZIN, N.K. Interpretative biography. London: Sage, 1989.

DUBAR, C. A socialização: construção das identidades sociais e profissionais. São Paulo: Martins Fontes, 2005.

DURKHEIM, E. The elementary forms of the religion life. New York: The Free, 1965. 
DURKHEIM, E. Educación y sociología. Barcelona: Peninsula, 1975.

ECCLESTONE, K; BIESTA, G.; HUGHES, M. (Eds.). Transitions and learning through the lifecourse. London: Routledge, 2010.

ELIAS, N. The society of individuals. Oxford: Blackwell, 1991a.

ELIAS, N. The symbol theory. London: Sage, 1991b.

ELIAS, N. The civilizing process. Oxford: Blackwell, 1994.

FERRÉS I PRATS, J. La educación como industria del deseo: un nuevo estilo comunicativo. Barcelona: Gedisa, 2008.

FREUD, S. The Ego and the Id. In: STRACHEY, J. (Org.). The standard edition of the complete psychological works of Sigmund Freud. New York: Norton, 1961.

GHEORGHIU, M.; GRUSON, P.; VARI, J. Trocas intergeracionais e construção de fronteiras nas experiências educativas das classes médias. Educação E Sociedade, Campinas, v. 29, n. 103, p. 377-399, 2008.

GIDDENS, A. Modernidade e identidade pessoal. Oeiras: Celta, 1994.

GOFFMAN, E. A apresentação do eu na vida de todos os dias. Lisboa: Relógio d'Água, 1993.

GUERREIRO, M.D.; ABRANTES, P. Como tornar-se adulto: processos de transição na modernidade avançada. Revista Brasileira de Ciências Sociais, Rio de Janeiro, v. 20, n. 58, p. 157-175, 2005.

INGLEHART, R. Mapping global values. Comparative Sociology, v. 5, n. 2-3, p. 115-136, 2006.

HOSKINS, J. Biographical objects: how things tell the stories of people's lives. New York: Routledge, 1998.

LAHIRE, B. Homem plural: os determinantes da acção. Petrópolis: Vozes, 2002.

LAHIRE, B. El espíritu sociológico. Buenos Aires: Manantial, 2005.

LAVE, J.; WENGER, E. Situated learning: legitimate peripheral participation. Cambridge, Mass.: Cambridge University, 1995.

MEAD, M. Coming of age in Samoa. New York: Blue Ribbon, 1927.

MERTON, R. Teoría y estructura sociales. México, DF: Fondo de Cultura Económica, 1987.

MOLLO-BOUVIER, S. Transformação dos modos de socialização das crianças: uma abordagem sociológica. Educação E Sociedade, Campinas, v. 26, n. 91, p. 391-403, 2005. 
PINTO, J.M. Sociologia e sociedade: reflexividade e ação. In: TORRES, A.; BAPTISTA, L. (Org.). Sociedades contemporâneas: reflexividade e ação. Porto: Afrontamento, 2008. p. 195-206.

PRESTO, S.; ALMEIDA, A.M. Fronteiras imaginadas: experiências educativas e construção das disposições quanto ao futuro por jovens dos grupos populares e médios. Educação \& Sociedade, Campinas, v. 29, n. 103, p. 401-424, 2008.

PUJADAS, J. El método biográfico: el uso de las historias de vida en ciencias sociales. Madrid: Centro de Investigaciones Sociológicas, 1992.

SOUSA SANTOS, B. Portugal: ensaio contra a autoflagelação. Coimbra: Almedina, 2011.

TORRES, A. Women, gender, and work: the Portuguese case in the context of the European Union. International Journal of Sociology, Armonk, v. 38, n. 4, p. 36-56, 2009.

TURNER, J.; STETS, J. Sociological theories of human emotions. Annual Review of Sociology, Palo Alto, v. 32, p. 25-52, 2006.

WILLIS, P. Learning to labour: how working class kids get working class jobs? Ashgate: Aldershot, 1977.

Recebido em 11 de maio de 2012.

Aprovado em 10 de janeiro de 2013. 